Madrygal. Revista de Estudios Gallegos

ISSN: 1138-9664

\title{
De mapas e viaxes: un relato para debuxar a nación
}

\author{
Carme Fernández Pérez-Sanjulián ${ }^{1}$
}

Recibido: 24 de setembro de 2019/ Aceptado: 12 de maio de 2020

Resumo. Analízase neste traballo a significación do uso de mapas e percursos por territorios diversos en textos narrativos e ensaísticos de Ramón Otero Pedrayo (Os camiños da vida, Arredor de si, Fra Vernero, A romeiría de Gelmírez, Devalar, Pelerinaxes $I$ e artigos publicados en prensa). En todos eles constátase como a utilización dos elementos cartográficos e mais do motivo das viaxes serve á idea da consolidación dun discurso literario-cultural inserido nun proxecto ideolóxico nacionalista. Ao mesmo tempo, este proxecto debe ser situado no contexto do labor continuado que a intelectualidade galega deste período desenvolve para competir pola influencia no espazo público.

Palabras chave: Ramón Otero Pedrayo; mapas; viaxes; identidade nacional; literatura galega contemporánea.

\section{[es] De mapas y viajes: un relato para dibujar la nación}

Resumen. Se analiza en este trabajo la significación del uso de mapas y recorridos por territorios diversos en textos narrativos y ensayísticos de Ramón Otero Pedrayo (Os camiños da vida, Arredor de si, Fra Vernero, A romeiría de Gelmírez, Devalar, Pelerinaxes I y artículos publicados en prensa). En todos ellos se constata como la utilización de los elementos cartográficos y del motivo de los viajes sirve a la idea de consolidación de un discurso literario-cultural imbricado en un proyecto ideológico nacionalista. Al mismo tiempo, este proyecto debe ser situado en el contexto del trabajo continuado que la intelectualidad gallega de este período desenvuelve para competir por la influencia en el espacio público.

Palabras clave: Ramón Otero Pedrayo; mapas; viajes; identidad nacional; literatura gallega contemporánea.

\section{[en] About Maps and Travels: a Story to Draw the Nation}

Abstract. This paper analyzes the significance of the use of maps and routes through diverse territories in narrative and essay texts by Ramón Otero Pedrayo (Os camiños da vida, Arredor de si, Fra Vernero, A romeiría de Gelmírez, Devalar, Pelerinaxes I and newspapers and journals published in press). All of them show how the use of cartographic elements and the motive of travel serves the idea of consolidating a literary-cultural discourse embedded in a nationalist ideological project. At the same time, this project must be placed in the context of the continued work that the Galician intellectuals of this period develop to compete for influence in the public space.

Keywords: Ramón Otero Pedrayo; Maps; Travels; National Identity; Contemporary Galicien Literature.

Sumario. 1. Introdución: as relacións xeografía - literatura. 2. Mapas e viaxes na obra literaria de Ramón Otero Pedrayo. 2.1. Os mapas nos textos: da Galiza á Europa. 2.2. Percursos europeos e reflexión identitaria. 2.3. Mapa literario da Europa. 3. A modo de síntese. 4. Referencias bibliográficas.

Como citar: Fernández Pérez-Sanjulián, C. (2020): “De mapas e viaxes: un relato para debuxar a nación”, en Madrygal. Revista de Estudios Gallegos 23 Núm. Especial, pp. 141-151.

1 Universidade da Coruña. Departamento de Letras, Grupo de Investigación Lingüística e Literaria Galega (ILLA). Correo-e: carme@udc.gal; https://orcid.org/0000-0002-8227-1298. 


\section{Introdución: as relacións xeografía - litera- tura}

A xeografía literaria é un campo de investigación emerxente, enmarcado na reorientación que a reflexión crítica experimentou nas últimas décadas desde as categorías temporais ás espaciais, no que Fredric Jameson denominou spatial turn (1991: 154). Unha mudanza de perspectiva que se instala no espazo cultural occidental a partir do que se deu en chamar posmodernidade e onde se pon o acento, non só no papel decisivo que o espazo xoga nas producións culturais e literarias, senón que subliña a emerxencia dunha nova preocupación pola dimensión espacial e as espacialidades na epistemoloxía académica ${ }^{2}$. Unha reflexión que xa viña precedida polas achegas de diversas disciplinas e escolas, entre as que cabe subliñar pola súa transcendencia a de Foucault, que ao longo da década de 60 insisten na importancia de privilexiar o estudo do espazo fronte ao da Historia. Esta idea adianta moitos dos debates teóricos en que asenta o xiro epistemolóxico e que conduce á consideración de que, en palabras de Paul Smethurst (2000) existe un "cronotopo posmoderno" que se caracteriza pola substitución do tradicional modelo temporal e histórico por outro que pon unha énfase maior na dinámica espacial.

Como consecuencia deste xiro espacial, foi tomando corpo a idea de que a literatura ten, tal como sinala Franco Moretti, unha natureza Ortgebunden, ligada ao lugar (1997: 5). En concreto, este autor desenvolveu influentes traballos, como o Atlante del Romanzo Europeo 1800-1900 onde se cartografan multitude de lugares que aparecen en determinadas obras senlleiras da literatura europea. Nel, e como un dos seus obxectivos, Moretti indica que pretende demostrar que a xeografía é un aspecto decisivo do desenvolvemento e da invención literaria: unha forza activa, concreta, e que deixa as súas pegadas nos textos, nas tramas e nos sistemas de expectativas (Ibid.: 3).

Nesta confluencia entre disciplinas científicas, sublíñase que a literatura é quen de construír xeografías (até o punto de que en moitos casos o coñecemento dos espazos se produce grazas ás obras literarias) e, así, desenvólvese o concepto de xeoliteratura, que se presenta como lugar de interrelación dialéctica do territorio, dos espazos culturais e das literaturas (Domínguez Prieto 2010).

En resumo, aquel xiro espacial, ese cambio de focaxe, levou a que unha parte da crítica deixase de lado un certo modelo de lectura tradicional, onde os espazos representados nas obras eran analizados apenas como un espello do real, e a que centrase a súa reflexión en aspectos menos explorados, tales como a constitución do concepto de paisaxe ou a reflexión sobre a súa función ideolóxica, ou tamén na interpretación dos elementos cartográficos inseridos nos textos. Igualmente sobre aqueles xéneros onde a dimensión espacial ocupa un lugar privilexiado, como por exemplo, a literatura de viaxes.

Esta abordaxe crítica ten sido explorada entre nós recentemente, por exemplo, por María López Sández (2008, 2010, 2011), nomeadamente no seu traballo Paisaxe e nación onde, entre outros asuntos, reflexiona sobre o papel exercido polas obras literarias desde o Rexurdimento no proceso de configuración do imaxinario territorial galego ou, de modo máis achegado á miña proposta, por Alberto Allegue Leira nas súas investigacións sobre o rendemento do tema do relatos de viaxes pola Galiza no primeiro terzo do século XX $(2010,2011)$.

Ao mesmo tempo, e antes de nos centrar na análise dos textos propostos, é tamén pertinente lembrar unha das consideracións que Xoán González-Millán propuxo no seu día para estudarmos a literatura galega de preguerra, a dialéctica entre un espazo público hexemónico e un contraespazo público emerxente que procura a súa "esfera autónoma", onde o espazo público hexemónico non é unicamente un marco de creación de opinións discursivas, senón a plataforma para a formación e institucionalización de identidades sociais e nacionais; fronte a ese espazo hexemónico, os novos espazos (contraespazos) que os grupos sociais marxinados ou periféricos procuran crear xeran unha relación de conflito desde posicións de desigualdade (1995: 19-23). Nesta liña, concordamos con Allegue Leira cando afirma que neste período existe

\footnotetext{
Sinala Fernando Cabo que é esta "una tendencia inextricablemente ligada al análisis crítico de la globalización que, en buena medida, procura adaptar el análisis marxista a los requerimientos de las nuevas condiciones del mundo contemporáneo. Y resulta fácilmente constatable hasta qué punto esta reorientación del análisis social hacia el espacio ha dejado una profunda huella en el estudio de las identidades culturales" (2004: 27).
} 
a conciencia dunha disputa nun ámbito público 'emerxente' que desexa expresarse en galego, e ten como 'horizonte de experiencia' o marco galego, fronte a outro ámbito público, máis poderoso e consolidado, que se expresa en español e que conforma unha identidade social e cultural en clave española. (2010: 18)

Na miña opinión, é neste contexto de esforzos que se realizan para competir pola influencia no espazo do público e, ao tempo, sob a vontade de consolidación do discurso nacionalista, onde hai que encadrar a utilización reiterada das viaxes e dos mapas como motivo literario, así como tamén a publicación de relatos de via$\mathrm{xes}^{3}$, por parte de autores galegos do primeiro terzo do século XX e, moi especialmente, de Ramón Otero Pedrayo.

\section{Mapas e viaxes na obra literaria de Ra- món Otero Pedrayo}

\subsection{Os mapas nos textos: da Galiza á Europa}

Como afirmamos en 2003, non é o gosto do xeógrafo o que está tras da recorrente utilización do tema do mapa que vemos na obra literaria do autor de Trasalba. Lembremos apenas a representación do mapa da Galiza ${ }^{4}$, no texto máis coñecido, a emotiva escena en que Adrián Solovio, obedecendo aos desexos do seu tío D. Bernaldo, pendura o mapa de Fontán fronte ao leito do moribundo e vai alumeando cunha candea aqueles lugares que o vello sacerdote lle indica. Nese momento, o percurso ficcional sobre o mapa permite, con todo o potencial didáctico que as representacións gráficas posúen, tornar visíbel unha realidade non evidente pois facilita a conceptualización de algo abstracto como é a idea de nación (Fernández Pérez-Sanjulián 2003: 145).

As referencias ao Fontán van ser constantes ao longo da obra deste autor: noutros romances $\left(\right.$ Adolescencia $\left.^{5}\right)$, en varios dos seus ensaios sobre a paisaxe ("Encol da aldeia", "A aldea galega no seu decorrer histórico"...) ou en numerosos artigos ("O Fontán en Bos Aires"6, "Variación no Fontán" "...). Con interesantes matices entre eles, en todos estes textos pódese constatar como o mapa é utilizado como elemento referencial simbólico; nuns casos, como imaxe plástica da nación, dotada dun evidente valor didáctico xa que facilita que as persoas que o contemplan, para alén de localizaren un ou outro punto xeográfico concreto, perciban a idea de conxunto e que, mesmo, cheguen a identificar conceptos até ese momento para elas inexistentes. En concreto, en "O Fontán en Bos Aires", o autor describe o poder de suxestión que exerce o mapa, despregado diante das persoas emigradas que asisten a unha conferencia:

Centos de olladas galegas o consideraron. En moitas houbo báguas, en todas a lediza dunha revelación, lembranza feita de súpeto corpo e claridade diante dos ollos. Naquila conferencia díuse un caso maravilloso e quizáis único na historia das conferencias: era o mapa quen guiaba e falaba polas palabras do conferenciante [...]. Era o mapa quen falaba operando taumatúrxicamente coa gracia e a beleza dos nomes na lembranza [...]. E coa derradeira frase ritual das conferencias comenzóu a interna lección do mapa. Agora falaba baixiño ao ouvido e ao corazón de cada ún. Tiña para todos amores e lembranzas [...]. E na imaxinación dos emigrados a campana do seu lugar, o acento da súa comarca rubían das néboas mestas a unha nova e consoladora verdade". (Otero Pedrayo 1973: 364-365; as itálicas son nosas)

O mapa interpela directamente as persoas que o contemplan e, así, tras a primeira percepción impresionista (a evocación do lugar, aldea ou bisbarra concreta de procedencia), permite a intelección dunha unidade máis ampla,

3 A reflexión e o debate que se desenvolveu nestes anos en relación co concepto de 'cosmopolitismo', non só fronte ao discurso público hexemónico, senón tamén no ámbito interno do sistema galego (propiciado polas críticas dalgúns escritores novos), están profundamente ligados con estes temas. Sobre este asunto, véxase Allegue Leira e Fernández Pérez-Sanjulián 2014.

4 Tal como sinala María López Sández, “dada a importancia da cartografía para a representación que a comunidade se fai do seu territorio, era case inevitábel a súa presenza nunha obra que practicamente adquire a dimensión de tratado teórico sobre o imaxinario territorial" (2008: 91).

5 Nesta novela publicada en Buenos Aires aparecen de novo ligados os temas da viaxe e o mapa. O pai do protagonista, xa mortalmente enfermo e levado por "un afán romántico de despedida e iniciación para el hijo" (Otero Pedrayo 1944: 171), agasállao cunha viaxe de seis días por Galiza como premio por ter rematado o Bacharelato. Ao regreso a Ourense, o mozo José Ramón reflexiona, a partir da visión do mapa, sobre a experiencia que vén de interiorizar: "No era el "Fontán" colgado en el despacho, un frío esquema. (...) En seis días José Ramón alcanzó un grado doctoral en el amor y sentimiento de Galicia” (1944: 164).

Publicado en La Noche (2/12/1947), aquí utilízase o texto da edición de Carlos Baliñas (Otero Pedrayo 1973). Neste caso publicado en 1975 baixo un dos seus habituais pseudónimos, o de Santiago Amaral. 
común para todas elas. Para alén diso, pódese observar como o mapa funciona tamén como elemento aglutinador dos membros da comunidade, pois tan galegas son as persoas emigradas como as que viven no país. Pertencen á comunidade aqueles e aquelas que atopan o seu lugar no mapa, isto é, os que se recoñecen como connaturais, aínda que vivan fóra ou xa teñan nacido na emigración. Deste modo, o mapa fica convertido nun poderoso instrumento que permite reforzar o continuum identitario que se mantén entre as dúas beiras do Atlántico.

Noutros textos, por exemplo en "A aldea galega no seu decorrer histórico", é utilizado como subtítulo: "Diante do Fontán". Neste caso, o valor referencial do mapa funciona de modo diferente pois, na altura da publicación do artigo (1965), pódese afirmar que ese mapa constitúe unha referencia xa relativamente asentada entre o público lector da obra do autor de Trasalba ${ }^{9}$. O autor colócao nun lugar preferente, a modo de friso que orienta toda a análise que logo se vai desenvolver. Non funciona, por tanto, como unha simple ilustración senón que posúe un valor esencial (no estrito sentido etimolóxico), no que vén ser un dos múltiplos recursos que Otero utiliza para, parafraseando a súa propia terminoloxía, o 'desvelamento' da nación. Aquela referencia incorpora ao texto, desde o seu inicio, a imaxe da Galiza como entidade única, como concepto político existente (en clara oposición á realidade negada no franquismo e non só), aquí representada a través desa abstracción convertida nunha sorte de 'fotografía' do espazo, que é o mapa. Neste sentido, á hora de analizarmos a eficacia da incorporación deste elemento, cómpre ter en conta que

Coa cartografía prodúcese un efecto de inmediatez perceptiva, de mímese, que oculta o carácter construído, cultural e fondamente ideolóxico do mapa. A isto contribúe a súa dimensión icónica, a súa base semiótica na transposición por semellanza, o seu carácter non enteiramente arbitrario (por máis que recoñecida e inevitabelmente convencional) e mesmo o seu emparentamento coa ciencia matemática, que o imbúe dunha aura de neutralidade incontestábel. (López Sández 2010: 74-75)

A partir de todos os exemplos citados, pódese afirmar que o uso literario e metafórico que Otero deu á Carta Geográfica de Fontán serviu para a configurar como un elemento referencial, pois converteuna nun signo, ao pasar a posuír un significante e un significado. E como todos os signos, dotado dunha enorme capacidade de suxestión (Fernández Pérez-Sanjulián 2003: 147-148), tal como se foi demostrando co paso do tempo.

De por parte, a utilización do mapa da Galiza en Otero non se limita só ao aproveitamento do Fontán. En 1929 publica Pelerinaxes I, o volume que recolle o relato da viaxe que desde Ourense a Santo André de Teixido fixeran Ben-Cho-Shey, Risco e el propio, e para a capa do libro escolle a imaxe dun mapa, en concreto, un debuxo do contorno da Galiza onde aparece marcada a rota da viaxe realizada. Esta representación do itinerario no marco do esquemático deseño subliña o valor simbólico da viaxe realizada por "uns galegos, nin turistas nin deportistas" (Risco 1929: 7) que aspiran a percorrer a súa terra con declarada vontade de coñecemento e, tamén, de compromiso profundo cun proxecto de carácter identitario:

Abonda qu'algunhas almas abertas s'acheguen â terra con devozón e amore, que se dean a percorrela cos pés e cos ollos, sintindo medrar nos curazós o sentimento filial e facendo de cada santuario da fé, de cada capela consagrada pol-a

8 A seguir, o artigo comeza do seguinte modo: “O Fontán, entre as moitas regalías súas, luce a de rexistrar polas súas cabeceiras, as eirexas, as costelaciós das parroquias da Galiza. [...] O fermoso mapa conselleiro, grave e ledo, ten para nós, os vellos camiñantes das estradas galegas, a emoción sempre nova do hourizonte e o consóo e fortecemento dun desenrolo de memorias. [...] E asín o Fontán e as presencias que o povóan, invitan a unha meditación sobre a aldea galega. Elo siñifica unha chamada sobre realidás e procesos esenciás" (Otero Pedrayo 1965: 133).

9 Entre moitas outras (hai múltiplas referencias a este asunto de Cunqueiro ou de Manuel María, por exemplo), escollemos un comentario de Carlos Martínez-Barbeito onde, a partir da evocación da escena de Adolescencia antes citada, comenta: "En Otero aprendí a ver con los ojos -y no sólo con los del cuerpo- esa adorable maraña de trazos que a muchos no dirá nada pero que a nosotros, a Otero y a los que de él aprendimos, sobre todo si estamos lejos de lo que es tan nuestro, nos hace entornar los párpados, apretar los labios y sentir en la garganta algo como una sequedad que nos obliga a tragar saliva. Gracias a Otero, nos decimos entonces, sabemos que Galicia non es sólo un mapa o un tratado o un poema o una nostalgia, sino un cuerpo en plena vida, con sus órganos y vísceras que son los sistemas orográficos, los grandes fachos, las corrientes fluviales, las tierras o países (...). Todo eso que Otero ha sabido ver como nadie había visto, la tierra viva de Galicia, su mar y su aire, nos habla, nos aprieta la mano, nos dice los que hemos de mirar, lo que hemos de amar" (Martínez Barbeito 1958: 71-72). 
tradizón popular, un altar d'amor â Patria Galega, onde ofrendarlle a adicazón cumprida das suas vidas, de todo o seu traballo, de todal-as suas capacidades e energías. (Risco 1929: 8-9)

O mapa representado na capa resume ben o proxecto que se presenta no libro: o percurso demorado a través do espazo nacional só cobra sentido na medida en que asenta na procura dun coñecemento integral do país, da comprensión do que os viaxeiros consideran a auténtica realidade nacional (isto é, do seu espírito). Tal como sinala Alberto Allegue,

Parece evidente que un dos obxectivos procurados é divulgar a esencia da "nación" tal e como se concibe por parte do nacionalismo conservador (encarnada no mundo rural, anterior á industrialización, que se presenta como atemporal), algo que viría corroborar a súa existencia, así como promover unha especial relación con ela, que busca a "identificación" ou a "comuñón", que pretende ser máis profunda que o simple espectáculo que se lle ofrece a un turista. (Allegue Leira 2011: 198)

$\mathrm{O}$ relato da viaxe inscríbese, en suma, nun proxecto máis extenso que ten como finalidade a elaboración dun discurso ideolóxico de carácter identitario, un proxecto que Otero, ao igual que outros coetáneos seus como Risco ou Castelao, asume coa vontade de o dotar dun discurso narrativo consistente, no convencemento de que a identidade galega só existe en tanto que existe un discurso que a conforma (Salinas 2011: 183).

En todo caso, por máis que os exemplos relacionados co Fontán ou outras representacións da Galiza sexan as máis coñecidas, non remata aquí o rendemento que Ramón Otero Pedrayo tira deste motivo do mapa e das viaxes nas súas obras. Se até aquí revisamos o modo en que Otero desenvolve o concepto da identidade por medio do mapa da Galiza, noutros textos da súa autoría é o mapa de Europa o que detenta un singular protagonismo. Isto é o que acontece, por exemplo, no seu romance Devalar (1935), onde o vai utilizar para enunciar, a través do fío do pensamento de Martiño Dumbría -aquel mozo que, xunto con Pauliños Fontenla, representaría, segundo Carvalho Calero (1975: 666-667 e 1982: 123), a xeración do Seminario de Estudos Galegos-, unha reflexión sobre a relación da Galiza con outras terras da Europa.

O fragmento escollido sitúase, dentro do discurso narrativo da novela, no final dunha longa reflexión do protagonista. Ao longo de tres noites, Martiño Dumbría revisa mentalmente "os seus tres estadios do sentimento do coñecemento amoroso de Galiza", e, así, na primeira noite, imaxina a Galiza antes de ser habitada; na segunda, a Santiago como meta final de milleiros de xeracións; e, na terceira noite:

No mapa da Europa (...) miraba â Galiza. O lirismo faguíase a soia realidade. Contra a política, economía, historia de tono, atreboada mistura das rúas, a Galiza xurdía cinguida âs outras patrias irmáns no arelare. Estratificábanse no mapa as estaxes da historia. Locían ca novidade eterna as paisaxes eleitas. $\mathrm{O}$ esenzal pende do anceio de cada terra. Todas teñen o seu, calado e brilante, alagado ou aparente, consecoente ou non co destiño. Por un pequeno intre foi o mozo tod'a a súa xerazón. Simpáticamente arelaban n-il os mozos labregos afondidos n-aquil hora no ensono vexetal, os mociños, as rapazas, todos os qu'il coñecera, i-os que endexamáis tiña falado.

Sentía Dumbría que unha xenerazón, soio unha xenerazón que tivera a heroica concenza da trascendentalidade do intre seu, soio unha, a súa, a dos mociños, faría do lirismo, historia. (Otero Pedrayo 1935: 76; as itálicas son nosas)

Ao igual que na xa citada escena de Arredor de si, tamén aquí o mapa se presenta como un elemento decisivo para a toma de consciencia da persoa que sabe ler entre as súas liñas; de feito, neste caso, vai funcionar como detonante da primeira reflexión de carácter definidamente política do protagonista, ou, dito dun modo máis exacto, reflicte unha primeira aproximación a un compromiso galeguista. Martiño Dumbría recoñece o seu país no conxunto europeo en que Galiza está, natural e historicamente, incluída mais, con todo, o que realmente considera esencial é o arelar común das patrias irmás, ese anceio de cada terra; isto é, a vontade de ser nación, o desexo dunha autonomía política ou, mesmo, da independencia, subxace nestas liñas.

Por outra parte, o mapa preséntase, máis outra vez, cunha función aglutinadora, pois convoca simbolicamente aos e ás habitantes da nación, e, así, Martiño, nese instante máxico de recoñecemento, imaxínase como se nel se concentrasen as identidades de todos os mozos e mozas do seu tempo, considera que nel arela toda a mocidade galega; por tanto, representa esa idea de unidade, de comunidade imaxinada, no sentido definido por Benedict Anderson (1993: 23-25), que Otero Pedrayo 
expón repetidamente ao longo de moitos dos seus textos. Deste modo, a referencia ao mapa de Europa afástase da convencional representación do conxunto de estados e aproxímase ao deseño dunha configuración diferente que, en Arredor de si, aparece reflectida a través dos pensamentos de Adrián Solovio:

A novidade de Europa, a que ela agarda, a que xustificará pra sempre no mundo (...) é (...) o descobremento e maioría d'edade de todol'os pobos que a compoñen, o xurdimento de todal'as yalmas coleutivas, nacionales. (...) Adrián (...) maxinaba o futuro mapa da Europa. As fronteiras non eran liñas de aduanas sinon vidales zonas de transición entr'as armoñosas concenceas dos pobos. (Otero Pedrayo 1930: 151; as itálicas son nosas)

Ese futuro mapa da Europa está composto a partir do recoñecemento das diferentes identidades nacionais, daquelas outras "patrias irmás no arelare" que Martiño Dumbría vía reflectidas naquela carta xeográfica que o interpelaba e, de camiño, o levaba da man cara á reflexión identitaria. Unha concepción de Europa diferente da configurada arredor dos estadosnación, pois, como se indica en moitos outros dos seus textos, nese novo mapa político que se está a deseñar, son as nacións periféricas e/ ou sen estado as que deben pasar a ter un papel máis relevante ${ }^{10}$.

\subsection{Percursos europeos e reflexión identita- ria}

Para alén dos mapas que Otero Pedrayo explicitamente dota dun valor protagonista, son moitos os itinerarios viaxeiros que o autor coloca nos seus textos e que, nunha liña coincidente co anteriormente exposto, utiliza como elementos clave para fixar no público lector algúns dos seus ideoloxemas centrais, xa que, como indica Francisco Salinas, para el "a viaxe é un método de aceso ao coñecemento do país e á configuración dun territorio que se pretende converter en nación" (2011: 186). Non resulta, pois, novidoso insistir na funcionalidade diexética do motivo das viaxes en grande parte da produción do noso autor, mesmo, nalgúns casos, abondosamente estudadas como eixo vertebrador das obras -como por exemplo en Arredor de si ou en relatos como "Dona Xohana e Don Guindo", incluído no volume Contos do camiño e da rúa (1932).

Como acontecía coa incorporación dos mapas ao discurso ficcional, na maior parte dos casos as viaxes narradas son utilizadas para trasladaren a experiencia individual (neste caso a través do relato do proceso de procura, aprendizaxe, transformación...) mais tamén para introduciren outros temas intimamente relacionados con determinados discursos ideolóxicos que o autor desenvolve a través dos seus textos. Non resulta, pois, estraño detectar como moitos deses itinerarios posúen un elevado valor simbólico e que, de seu, funcionan como elementos contrastivos que permiten, desde outra perspectiva, unha aproximación complementar á reflexión identitaria sobre o propio territorio nacional. Este sería xustamente o caso da viaxe de Santiago a Roma que se narra n'A Romeiría de Gelmírez (1934), concibida como unha sorte de Camiño de Santiago á inversa. Para alén do intenso labor de recreación erudita do universo medieval europeo, o que aquí nos interesa resaltar deste romance é como a viaxe funciona como elemento vertebrador da reflexión identitaria (constante ao longo de todo o itinerario) que o autor proxecta através da figura de Xelmírez, construído case como unha sorte de figura protonacionalista ${ }^{11}$.

Con todo, neste punto parécenos especialmente pertinente centrar a análise naqueles

10 Obviamente, o espazo deste artigo non nos permite unha revisión exhaustiva dos elementos cartográficos que aparecen ao longo das páxinas oterianas. Como xa se indicou, é este un motivo de grande rendibilidade na obra do escritor que, co paso do tempo, incorpora toda unha chea de significados autorreferenciais. Moitas desas alusións a mapas van ser vagas (por máis que carregadas dun profundo poder suxestivo) e, no caso de remitiren a mapas da Galiza, parecen evocar sempre o Fontán, aquel mapa que Otero transformou en motivo literario dotado dun significado complexo. Isto acontece, por exemplo, no guión do filme Camino de Santiago, elaborado por Otero Pedrayo en 1952 e recentemente editado pola profesora Laura Tato, onde este elemento é utilizado, para a "visualización da evolución histórica do avance sobre Europa das lexións romanas; os mapas medievais ou renacentistas plasmando os camiños a Compostela por toda Europa e, por último, o mapa de Galiza" (Tato Fontaíña 2018: 37).

11 No romance, a voz do narrador expón de modo reiterado a idea de Galiza como referente común de identidade (até o punto de utilizar, mesmo, o termo patria), por medio, sobre todo, da personaxe de Xelmírez e, moi especialmente, dos momentos de ensoñación: "Nos intres vagarosos de proieutos creadores o Prelado de peitos na almeas da torre, deixando voar a maxinación, sentia a presencia vivente da Galiza como a fermosa Patria sen comparanza que se pode abranguer e bicar como unha nái" (Otero Pedrayo 1934a: 57). 
casos en que se presentan percursos viaxeiros onde se deseñan rotas que seguen un esquema periferia-centro-periferia. En concreto, imos deternos no relato dalgunha das viaxes que realiza Adrián Soutelo, unha das personaxes máis relevantes do romance $O s$ camiños da vida (1928), onde protagoniza outra das paradigmáticas viaxes formativas tan frecuentes no textos de Otero ${ }^{12}$. En concreto neste texto podemos falar de dúas viaxes distintas, unha, a viaxe a París, e, despois, a viaxe por Irlanda, demoradamente descrita nunha sorte de memorias, presentadas a modo de historia intercalada baixo o título de "O coto de Ushna" (Otero Pedrayo 1928: III, 6-17); estas dúas viaxes preséntanse como acontecementos que impactan profundamente na sensibilidade do galego e que van contribuír de modo esencial á configuración da súa ideoloxía.

Nunha data indeterminada entre 1830-1840, o mozo Adrián é enviado a estudar a París, un espazo especialmente significativo desde o punto de vista da centralidade cultural e da produción de ideas, mais tamén da política (en tanto que capital dun estado cun papel fundamental no equilibrio político europeo do XIX e, á vez, especialmente centralizado e xacobino). Alí Soutelo coñece os exiliados, persoas doutros espazos non hexemónicos (e, moi importante, non recoñecidos na altura como entidades políticas soberanas), que se van converter en referentes importantes no seu proceso de aprendizaxe.

A través destas personaxes, Otero introduce dous espazos diferentes, Irlanda e Polonia, conectados entre si pola súa situación de terras submetidas a outros estados e, tamén (e esta cuestión posúe un especial relevo na ideoloxía do autor) polo relevante papel que, no proceso de resistencia, tivo nelas a relixión católica. Ao tempo, resulta evidente que esta escolla é debedora da valoración da que gozaban estas nacións, moi especialmente Irlanda, no sistema cultural galego de preguerra onde funcionaron como claros referentes de analoxía ${ }^{13}$.

Nomeadamente, as figuras dos irmáns irlandeses Edith e O'Bryan, xunto coa do polaco Potocky, son presentadas como referentes de identificación que, finalmente, van funcionar como desencadeantes do compromiso político do galego Soutelo. Así evoca Adrián Soutelo a profunda pegada que este encontro provocou na súa visión do mundo:

Tardei en atopar en París o centro e a compaña doadas para o meu xenio. Un serán fun a Versalles. (...) Andei rondando un grupo de persoas que me interesaban. Axiña souben os seus nomes: Potocky, O'Bryan, con outros dous ou tres emigrados, alancaban polas alamedas, mal fateados, con indumentos contradictorios, como levados polo vento dos mortos igual que as follas murchas. ¡Mais nos seus ollos brillaba unha luz serena, contida, fatal, dando ás veces un brillar súpeto de pistolazo! A conversa estralaba en anacos labarecentes para caer logo en espaciados silenzos dominados polo aleteo da grande idea fixa: a patria escravizada. Eran náufragos salvados da catástrofe das súas terras; e xuntaban as súas paixóns nun arelar polo de entón practicamente quimérico. Polonia, Irlanda, Hungría, antergas terras gardadoras dos ósos das razas ceibes, ficaban envolveitas nas triples redes da burocracia, do militarismo, da xustiza e do ensino estranxeiros. $\mathrm{O}$ vasto peito de Potocky estralaba en salaios ó pensar na lingua da súa nai varrida das escolas, arrincada das imprentas, botada como unha xerga maldizoada da cátedra sagrada. O'Bryan, os ollos griseiros perdidos nunha liña de mar e ceo, pensaba ouvir o bater das augas atlánticas nos rochedos da costa das sagas. Os cisnes brancos da Irlanda morrían un a un nos lagos mornos; ano tras ano chegaría tempo en que os rapaces encherían a escola e o templo cantaruxando nunha lingua estraña e bronca. Quizais ata dubidasen da fe nacional diante do martelar das pasaxes bíblicas polo pastor protestante. Ós emigrados non se preguntaban os nomes nin as patrias, Nos meus ollos coñeceron que eu tamén era un emigrado, e eu, falando con eles, sentín xurdir ceibe aquela visión da Galiza que ata entón soamente se me tiña presentado como unha néboa de rapaz. (Otero Pedrayo 1928: 63-65; as itálicas son nosas)

Os tres teñen en común a súa condición de persoas loitadoras pola liberdade das nacións, mais os irmáns irlandeses O'Bryan posúen moita maior relevancia, tanto diexética como

12 Non é preciso insistir aquí en que moitas desas viaxes, ao igual que acontece coa de Adrián Solovio, están concibidas como o relato dun camiño de autocoñecemento, necesario para a autoafirmación do protagonista, que remata na asunción dun compromiso con Galiza, de tinte protonacionalista ou xa directamente nacionalista, por parte dos seus protagonistas.

13 Beramendi sinala a diferente utilización do que el denomina as "analoxías étnicas", onde inclúe Irlanda, e a dos “análogos universais", onde sitúa Polonia, por parte do discurso galeguista (2007: 586-589). Unha análise da rendibilidade específica de Polonia como referente de analoxía pódese ver en Fernández Pérez-Sanjulián 2017. 
ideolóxica, no relato. Así, a partir do contacto con eles, o mozo Adrián Soutelo, realiza un primeiro achegamento ao mundo céltico do punto de vista cultural: a poesía do Norte, as lendas de Ossián, as vidas dos druídas e dos santos, a Idade Media... Xa engaiolado, acepta a proposta de acompañalos a Irlanda, e deste modo, a viaxe e, ao tempo, o namoro con Edith O'Bryan vanse configurar como dúas experiencias inesquecíbeis e definitivas para o fidalgo galego.

A segunda das viaxes (París-Bretaña-Irlanda) permite ao narrador, para alén de describir brevemente o seu paso pola Bretaña ${ }^{14}$, centrarse na descrición da situación irlandesa: a situación de extrema pobreza en que se acha a illa (a fame, as mortes e os embargos) e mais o compromiso coa loita pola Independencia ("a loita sagrada") do pobo irlandés ${ }^{15}$. Máis unha vez, todo o relato configúrase como unha viaxe de formación que, neste caso, xira arredor da interiorización dos elementos que poderían ser definidos como códigos identitarios, e que ten o seu punto central na visita a un lugar de especial relevancia simbólica que, segundo a tradición, representa a unión de Irlanda: o outeiro de Uisneach.

Iste é un dos fogares da tradición irlandesa. Asegún as nosas crónicas gaélicas, os Firbolgs tomaron terra na illa no ano[s] 3266; seu xefe, Dala, demarcouna entre os seus cinco fillos. As herencias de todos atestán n'iste montiño que figura non ter valor. (...) ¡Deus sexa louvado! Chegará un día no que todol-os irlandeses nos xuntemos ceibes no coto de Ushna! (Otero Pedrayo 1928: III, 15-16)

Resulta evidente que a singularidade deste outeiro vén dada por aglutinar en si varios dos elementos simbólicos da nación: a epopea dos pais fundadores, o estabelecemento da historia propia (as crónicas), así como a determinación física dun espazo simbólico que permite visualizar didacticamente a idea da cohesión nacional. E a visita a un lugar destas características, como semella evidente, non podía deixar de ser relevante para o mozo galego. Estamos no final da súa viaxe e o protagonista, unha vez percorrido o país e tendo observado de perto as duras condicións económicas e políticas en que vive a poboación irlandesa, comprende a urxencia da loita pola independencia ${ }^{16}$ e, aínda máis, interioriza as claves do discurso identitario. Isto último, tal e como el vai declarar anos despois ao seu sobriño (Ibid.: III, 100-103), vai ser definitivo na configuración da súa Weltanschauung galeguista ${ }^{17}$.

En resumo, resulta evidente o papel que o relato destas viaxes por Europa cumpre na diexese narrativa á hora de conformar a evolución do pensamento do protagonista mais, ao tempo, ao igual que acontecía coa utilización do mapa europeo de Devalar, é importante fixar a nosa atención nos lugares escollidos como obxecto da atención e na densidade ideolóxica que incorporan ao discurso.

O protagonismo concedido a espazos considerados periféricos, a aprendizaxe da solidariedade con outras patrias non necesariamente atlánticas, todo isto leva implícita unha posta en valor dun discurso europeísta vinculado (como en Devalar ou en Arredor de si) a unha idea de Europa como conxunto de nacións, ligadas por unha historia e uns referentes culturais semellantes, mais non dirixida desde os centros de poder ligados aos estados. Neste contexto, esa reconstrución ficcional do proceso de desenvolvemento da consciencia identitaria galega no século XIX en paralelo coa que se produciu noutros lugares da Europa implica un orgulloso exercicio de superación de autolimitacións e preconceptos aprendidos, ao presentar o relato da cuestión galega en pé de igualdade con outros contextos (como o irlandés ou o polaco) que viron recoñecida a súa entidade política por máis que se teña presente a existencia doutras reivindicacións identitarias aínda pendentes: “(...) Agora mesmo,

14 A comparación implícita con Galiza está sempre presente, tal como se evidencia na evocación de Corme e da Coruña a partir da visita a Saint-Malo (Otero Pedrayo 1928: III, 11).

15 Un compromiso total, representado no relato por medio de Edith O'Bryan, quen decide sacrificar a súa felicidade persoal (neste caso, a relación amorosa co galego) en función das necesidades patrióticas.

16 Ao longo da historia son moitos os momentos en que se establece unha analoxía, implícita ou explícita, entre a "nación irmá" e a Galiza, mais, con todo, esta é especialmente subliñada no final cando na despedida en Dublín os irlandeses ofrezan "[u]n mollo de curazós e de fusiles pra cando compriran en Galiza" (Ibid.: II, 17).

17 Convertido nunha sorte de figura paternal para o seu sobriño Paio Soutelo, transmítelle toda a experiencia recibida do contacto con outras terras, especialmente o que considera máis relevante, o sentimento de orgullo nacional que aprendeu dos seus amigos europeos. 
n'ista Europa que se gaba de ser tan culta hai moitas razas que sofren baixo a tiranía estranxeira. Pensaríase qu'están mortas si non falara a súa ialma nos versos d'algús poetas" (Ibid.: II, 43), en palabras de Adrián Soutelo.

\subsection{Mapa literario da Europa}

A referencia anteriormente citada aos poetas que poñen voz ás reivindicacións dos pobos lévanos a outra das formulacións do motivo cartográfico na obra do autor que nos ocupa: trátase do concepto, pleno de actualidade, de mapa literario. Nun artigo publicado en 1932 en El Pueblo Gallego, titulado "Mapa literario da Europa", Otero Pedrayo xustifica desde o inicio o seu interese por esta formulación por máis que non deixe de constatar nela unha certa condición problemática:

Somentes procuramos fixar a atenzón encol do nacer e vivir das formas literáreas do esprito, nun cruce de camiños que, xornaleiramentes, e hoxe con autoalidade crecedeira, é merecente de calcada e renovadora meditazón. Pois a vella polémica das forzas antitéticas, do universal co particolar, apaixoa agora no mesmo grado que nas grandes batallas escolástecas do medioevo. (Otero Pedrayo 1988: 142)

Máis adiante, de feito, reflexiona sobre a relación conflitiva entre este concepto e a afirmación das literaturas nacionais:

Igoal poidemos pensare dises grandes seres, neboentos por sobra de volume, que se acostuma a chamar literaturas nazonales. Incruso a de máis forte eixe no tempo e no espazo -a francesadescompónse en moitas pequenas literaturas. Manda na íntema realidade un rexionalismo e un nazonalismo contra a forma imperial da suposta unidade. Poidérase maxinar unha sorte de sindicalismo literario que enfeixe os poetas do mar, da malenconía, da bohemia, do agro, ou da rúa, por baixo das respeitivas unidades estatales manexadas na historia literaria. (...)

Hai as grandes figuras totalizadoras dunha tradizón ou dunha arela nazonal. Homero, Dante, Goethe. Tampouco elas fuxen dista lei vidal que lembramos [...]: ¿non son categoirías máis presentes na obra e no verbo que aquila sintética caraiterizaceón representativa de literaturas enteiras? Eles mesmos, de voltar á vida, ¿Qué xénero de sufraxio admirativo escolmarían? (Ibid.: 142) $)^{18}$

A partir do texto pódese concluír que existen unhas liñas, uns temas, un substrato común que configura o continuum cultural sobre o que asenta o que tradicionalmente se deu en considerar o pensamento europeo; un fluxo de ideas, unha estética, unhas referencias literarias e/ou culturais de todo tipo que, produto da relación e intercambio constante, non están directamente condicionadas polas fronteiras políticas, nomeadamente polas definidas polos estados nacionais desde o século XIX.

E esta é a idea central que Otero desenvolve longamente noutra das súas obras, Fra Vernero (1934), un romance que, se ben nunha primeira lectura semella ficar fóra das liñas temáticas habituais do seu discurso, constitúe un bo exemplo do interesante concepto de europeísmo sustentado polo autor, máis unha vez, exposto a través desa interrelación implícita, mais constante, entre Galiza e Europa ${ }^{19}$.

En Fra Vernero, a idea de Europa confórmase como un constructo histórico-cultural imprescindíbel á hora de entender ou elaborar as ideas, discursos ou expresións artísticas que se expoñen na narración. Así, nun primeiro momento, e a partir da peripecia vital de Zacharias Werner, o personaxe protagonista, asistimos a un relato demorado, e profundamente subxectivo, do espazo cultural directamente relacionado con el (Varsovia, Viena, Alemaña...),

18 Finalmente, despois de evocar algunhas desas figuras totalizadoras (Baroja, Azorín, Galdós, Barrés, D’Annunzio ou J. Conrad) conclúe: "Encol do fermoso grabado do Stieler locen, en cada terra, nomes, lembranzas, criazóns. Ningunha privada do seu senlleiro poeta. (...) Encol do mapa animado, procuremos a simpatía dos que diron voz ás terras, e estilo ás língoas do agro e do mar" (1988: 143).

19 Este aspecto xa foi subliñado pola crítica; véxanse as afirmacións de Carvalho Calero: "O galeguismo de Otero era un reintegracionismo en Europa. (...) Explícase así que na obra de Otero Pedrayo existan pezas como o Fra Vernero, que non son galegas senón europeístas" (1977: 134-135); tamén Cunqueiro: “O Otero Pedrayo, europeo, onde está verdadeiramente é en grande parte de A romería de Xelmírez, pro, sobre todo, en Fra Vernero (...). Neste libro está, en estampas, o século XVIII europeo. Unha ollada á vez extensa e fonda. Todo o gran século desenrólase diante da vista do leitor como unha fermosísima tapicería, dende Salzburgo ate a batalla de Fontenay. Coido que non hai, en toda a literatura europea, unha descripción tan fermosa daqueles anos que ao final reveláronse decisivos. (...) O que supón de conocimiento da historia e da cultura europea ese pequeno libriño, é verdadeiramente increíble" (Cunqueiro 1979: 94); ou aínda X. González Gómez (1985: 487). 
un espazo que para o público lector cobra un sentido máis complexo a partir da inclusión do capítulo V, aquel que leva por título "Europa" (1934: 61-78). Nese capítulo, situado significativamente no centro do romance, Otero Pedrayo propón unha viaxe por unha sorte de mapa literario-cultural da Centroeuropa de finais do XVIII: Café Pedrochi (Pádova) e Hugo Fóscolo; Salzburgo, os palacios vieneses e Mozart; Ermenonville e Xoán Xacobe Rousseau; as paisaxes literarias inglesas; Bretaña e Chautebriand; París e Voltaire; a Italia submetida ao dominio de Austria e Stendhal; Tubinga e Hölderlin, Schelling e Hégel e, finalmente, a modo de colofón, o final do século e tamén do Antigo Réxime, recreados a través do París da Revolución e da morte de André Chenier.

A través de todo este panorama de referencias afírmase a idea de que é esta mesta rede cultural o que constitúe, finalmente, o máis forte elemento estruturador europeo, o elo de unión que subxace entre territorios, linguas e posicións políticas diferentes. Ao mesmo tempo, e ligada de modo incontornábel á anterior, outra idea forza está implícita no texto: esta reflexión sobre os eixos que serviron para a construción non só dos referentes culturais do autor, senón tamén do modelo de pensamento do universo intelectual do seu tempo, está formulada desde a Galiza, un espazo non central e cun sistema literario aínda en fase de consolidación, a modo de brillante, e ousado, exercicio de afirmación do contraespazo público que se está a configurar. No fondo, o que se está a reclamar é o recoñecemento da participación galega nese espazo europeo, de novo en pé de igualdade con outras culturas, no que viría ser a construción dun mapa, por fin, policéntrico.

\section{A modo de síntese}

Sen dúbida, ao longo da produción literaria de Ramón Otero Pedrayo, a frecuente utilización literaria dos motivos de mapas e viaxes articúlase arredor da idea da consolidación dun discurso literario-cultural inserido no marco do proxecto ideolóxico nacionalista de que o autor é un dos protagonistas.

Este discurso constrúese, en concreto, a partir da revisión de temas caracterizadores (e prestixiados) do discurso hexemónico das elites culturais e académicas daquel tempo. Neste sentido, a incorporación nos textos oterianos de elementos cartográficos (con todo o valor engadido do seu carácter científico e, por tanto, de aparente neutralidade) e dos relatos de viaxes (que introducen implicitamente outros temas como o deslocamento no espazo, a aprendizaxe, a procura da/do outra/o...) está traspasada por unha vontade de reapropiación dalgúns dos referentes asentados na esfera pública prestixiada (centro/periferia, Europa como conxunto de nacións, posición do nacionalismo galego de principios de XX en relación coa do mapa europeo naquela altura...).

Por outra parte, as repetidas alusións a outras realidades nacionais funcionan como un poderoso argumento auxiliar para afortalar o discurso sobre a nación galega, que é a que se aspira a colocar no centro do debate. De feito, a reflexión sobre as interrelacións co espazo europeo está tamén presente de modo insistente noutros autores do período (Antón e Ramón Vilar Ponte, Leandro Carré, Castelao ou Vicente Risco, entre outros), o que demostra a relevancia que se lle concedía a este tema e que se xustifica na necesidade de dotar de lexitimidade o discurso galeguista no espazo público.

En suma, é esta liña discursiva a que determina a utilización reiterada do motivo das viaxes e dos mapas na obra dun autor como Ramón Otero Pedrayo, como auxiliar valioso do seu discurso de construción nacional galego.

\section{Referencias bibliográficas}

Allegue Leira, Alberto (2010): As viaxes pola nosa terra e as razóns da súa escrita no primeiro terzo do século $X X$. Tese de doutoramento inédita. A Coruña: Universidade da Coruña.

- (2011): "Catro escollas para escribir Pelerinaxes I", en C. Fernández Pérez-Sanjulián (ed.), Viaxes e construción do pensamento. Viaxes e viaxeiros na Galiza anterior a 1936. A Coruña: Universidade da Coruña / Fundación Vicente Risco, pp. 189-200.

Allegue Leira, Alberto e Carme Fernández Pérez-Sanjulián (2014): “Á volta do cosmopolitismo; unha lectura de Arredor de si como intervención”, Madrygal. Revista de Estudios Gallegos 17, pp. 13-25, DOI: https://doi.org/10.5209/rev_MADR.2014.v17.45734.

Amaral, Santiago (1975): "Variación no Fontán", Grial 50, pp. 528-530.

Anderson, Benedict (1993 [1983]): Comunidades imaginadas. Reflexiones sobre el origen y la difusión del nacionalismo. México: Fondo de Cultura Económica. 
Beramendi, Justo (2007): De provincia a nación. Historia do galeguismo político. Vigo: Xerais.

Cabo Aseguinolaza, Fernando (2004): "El giro espacial de la historiografía literaria", en A. Abuín e A.

Tarrío (eds.), Bases metodolóxicas para unha historia comparada das literaturas na península Ibérica.

Santiago de Compostela: Universidade de Santiago de Compostela, Servizo de publicacións e intercambio científico, pp. 21-43.

Carvalho Calero, Ricardo (1975): Historia da Literatura galega contemporánea. Vigo: Galaxia. (1977): "Otero Pedrayo: unha visión de Galicia", Grial 56, pp. 113-141.

(1982): Libros e autores galegos, século XX. A Coruña: Fundación Barrié.

Cunqueiro, Álvaro (1979): “Tres notas sobre Don Ramón”, en S. Cardeñoso (ed.), Nuestro amigo Ramón Otero Pedrayo. Vigo: Zero-Zyx, pp. 93-96.

Domínguez Prieto, César P. (2010): "Historiography and the geo-literary imaginary. The Iberian Peninsula: Between Lebensraum and espace vécu", en F. Cabo, A. Abuín e C. Domínguez (eds.), A comparative History of Literatures in the Iberian Peninsula. Amsterdam: John Benjamins, pp. 53-132.

Fernández Pérez-Sanjulián, Carme (2003): A construción nacional no discurso literario de Ramón Otero Pedrayo. Vigo: A Nosa Terra.

(2006): "A literatura de viaxes nos contextos de emerxencia literaria: o caso galego", en F. Salinas Portugal e Mª A. T. Maleval (eds.), Estudos Galego-Brasileiros 2. A Coruña: Universidade da Coruña, pp. 365-388.

(2017): "Polonia no horizonte das Irmandades da Fala", en J. Beramendi, U.-B. Diéguez, C. Fernández Pérez-Sanjulián, Ma P. García Negro e X. M. González Reboredo (eds.), Repensar Galicia. As Irmandades da Fala. Santiago de Compostela: Xunta de Galicia / Museo do Pobo Galego, pp. 169-184.

González Gómez, Xesús (1985): "Releitura de Fra Vernero", Grial 90, pp. 487-490.

González-Millán, Xoán (1995): “O discurso literario galego e a configuración dun espacio público nacional no primeiro tercio do século XX", en A. Casas (coord.), Tentativas sobre Dieste. Santiago de Compostela: Sotelo Blanco, pp. 13-29.

Jameson, Fredric (1991): Postmodernism, or the cultural logic of the late capitalism. London: Verso.

López Sández, María (2008): Paisaxe e nación. A creación discursiva do territorio. Vigo: Galaxia.

(2010): "Paisaxes e identidades: imaxinarios de colonización e imaxinarios de resistencia", en R.

Pérez Moreira e F. J. López González (eds.), Cultura e paisaxe, Santiago de Compostela: Universidade de Santiago de Compostela, Servizo de publicacións e intercambio científico, pp. 71-82.

- (2011): “A viaxe inacabada da literatura de viaxes: paradoxos, cuestionamento e transformación dun xénero”, en C. Fernández Pérez-Sanjulián (ed.), Viaxes e construción do pensamento. Viaxes e viaxeiros na Galiza anterior a 1936. A Coruña: Universidade da Coruña / Fundación Vicente Risco, pp. 29-42.

Martínez Barbeito, Carlos (1958): “Mi Otero Pedrayo", en Ramón Otero Pedrayo. A súa vida e a súa obra. Caracas: Homaxe da Galicia Universal, pp. 71-72.

Moretti, Franco (1997): Atlante del Romanzo Europeo 1800-1900. Turin: Eunadi.

Otero Pedrayo, Ramón (1928): Os camiños da vida. Santiago: Nós.

(1930): Arredor de si. Cruña: Nós.

(1934a): A romeiría de Gelmírez. Santiago: Nós.

(1934b): Fra Vernero. Santiago: Nós.

(1935): Devalar. Santiago: Nós

(1944): Adolescencia. Buenos Aires: Nova.

(1965): “A aldea galega no seu decorrer histórico", Grial 8, pp. 113-155.

(1973): “O Fontán en Bos Aires”, en Obras selectas I. Parladoiro. Artigos (ed. Carlos Baliñas). Vigo: Galaxia, pp. 364-365.

- (1988): Prosa miúda. Artigos non coleccionados (1927-1934) (ed. Aurora Marco). Sada: Ediciós do Castro.

Risco, Vicente (1929): "Prólogo", en Ramón Otero Pedrayo, Pelerinaxes I. A Coruña: Nós, pp. 7-10.

Salinas Portugal, Francisco (2011): "A experiencia da viaxe e a viaxe como experiencia literaria", en C. Fernández Pérez-Sanjulián (ed.), Viaxes e construción do pensamento. Viaxes e viaxeiros na Galiza anterior a 1936. A Coruña: Universidade da Coruña / Fundación Vicente Risco, pp. 179-187.

Smethurst, Paul (2000): The Postmodern Chronotope. Reading Space and Time in Contemporary Fiction. Amsterdam: Rodopi.

Tato Fontaíña, Laura (2018): “Introdución”, en R. Otero Pedrayo, Camino de Santiago. Guión para una película. Vigo: Galaxia, pp. 9-51. 